\title{
High resolution computed tomographic assessment of asbestosis and cryptogenic fibrosing alveolitis: a comparative study
}

\author{
N Al-Jarad, B Strickland, M C Pearson, M B Rubens, R M Rudd
}

\begin{abstract}
Background The aim of this study was to compare the distribution and configuration of lung opacities in patients with cryptogenic fibrosing alveolitis and asbestosis by high resolution computed tomography.

Methods Eighteen patients with cryptogenic fibrosing alveolitis and 24 with asbestosis were studied. Two independent observers assessed the type and distributions of opacities in the upper, middle, and lower zones of the computed tomogram.

Results Upper zone fibrosis occurred in 10 of the 18 patients with cryptogenic fibrosing alveolitis and in six of the 24 patients with asbestosis. A specific pattern in which fibrosis was distributed posteriorly in the lower zones, laterally in the middle zones, and anteriorly in the upper zones was seen in 11 patients with cryptogenic fibrosing alveolitis and in four with asbestosis. Band like intrapulmonary opacities, often merging with the pleura, were seen in 19 patients with asbestosis but in only two with cryptogenic fibrosing alveolitis. Areas with a reticular pattern and a confluent or ground glass pattern were the commonest features of cryptogenic fibrosing alveolitis (15 and 14 patients respectively) but were uncommon in asbestosis (four and three patients). Pleural thickening or plaques were seen in 21 patients with asbestosis and in none with cryptogenic fibrosing alveolitis.

Conclusion Apart from showing pleural disease high resolution computed tomography showed that confluent (ground glass) opacities are common in cryptogenic fibrosing alveolitis and rare in asbestosis whereas thick, band like opacities are common in asbestosis and rare in cryptogenic fibrosing alveolitis.
\end{abstract}

London Chest Hospital, London E2 9JX

N Al Jarad

M C Pearson

M B Rubens

R M Rudd

Royal Brompton and National Heart Hospital, London SW3 6HP

B Strickland

Reprint requests to: Dr R M Rudd

Accepted 1 March 1992

High resolution computed tomography is superior to chest radiography in investigating interstitial lung disease because there is less superimposition of structures, which allows a better assessment of the type, distribution, and severity of parenchymal abnormalities than is possible by chest radiography. ${ }^{1}$ Several recent studies have described the computed tomographic appearance of various diffuse interstitial lung diseases..$^{2-6}$
High resolution computed tomography is particularly valuable in the early detection of lung fibrosis in asbestos workers in whom the chest radiograph appears normal or shows only pleural disease. ${ }^{7-9}$ Yoshimura et al ${ }^{10}$ and Akira et $a l^{11}$ have correlated the types of shadows seen in the high resolution computed tomogram in patients with asbestosis with the histological findings at necropsy.

The differentiation between asbestosis and cryptogenic fibrosing alveolitis is often difficult, particularly when the extent of occupational asbestos exposure is unclear. The potential value of high resolution computed tomography in differentiating these diseases has not been assessed specifically. In one study computed tomographic features were investigated in 118 patients with different types of interstitial fibrosis, who later had open lung biopsy. High resolution computed tomography gave the correct diagnosis in $76 \%$ of cases compared with $57 \%$ of cases by plain chest radiography. ${ }^{12}$ The computed tomographic changes in patients with asbestosis in that study were described as being the same as those in patients with cryptogenic fibrosing alveolitis with the addition of bilateral pleural thickening, ${ }^{12}$ but only two patients with asbestosis were included.

We compared the findings of high resolution computed tomography in patients with cryptogenic fibrosing alveolitis and asbestosis to determine whether there are differences other than frequency of associated pleural changes.

\section{Methods}

PATIENTS

We studied 18 patients with cryptogenic fibrosing alveolitis (four women and 14 men, mean age 57 (range 33-75) years) and 24 men with asbestosis (mean age 59 (34-75) years). Asbestosis was diagnosed when fine mid to late inspiratory crackles and pulmonary opacities of

Table 1 Mean (95\% confidence interval) age and pack years of smoking in patients with asbestosis and cryptogenic fibrosing alveolitis. Difference between groups not significant

\begin{tabular}{lll}
\hline & & $\begin{array}{l}\text { Cryptogenic } \\
\text { fibrosing } \\
\text { alveolitis } \\
n=18\end{array}$ \\
\hline $\begin{array}{lll}\text { Asbestos } \\
n=24\end{array}$ & $59(56$ to 64$)$ & $\begin{array}{l}57(51 \text { to } 63) \\
29(20 \text { to } 38)\end{array}$ \\
\hline Pack (years) years of smoking & $26(19$ to 35) & \\
\hline
\end{tabular}


Table 2 Mean (95\% confidence interval) results of lung function tests expressed as percentage of predicted values ${ }^{i 5}$ in patients with asbestosis and cryptogenic fibrosing alveolitis

\begin{tabular}{|c|c|c|}
\hline & $\begin{array}{l}\text { Asbestosis } \\
n=24\end{array}$ & $\begin{array}{l}\text { Cryptogenic } \\
\text { fibrosing } \\
\text { alveolitis } \\
n=18\end{array}$ \\
\hline $\mathrm{FEV}_{1}$ & 76 (67 to 85$)$ & 82 (72 to 93$)$ \\
\hline FVC & 80 (71 to 88 ) & 91 (77 to 102 ) \\
\hline $\mathrm{FEV}_{1} / \mathrm{FVC}$ & 94 (85 to 103$)$ & 100 (91 to 109$)$ \\
\hline Total lung capacity & $89(81 \text { to } 97)^{\star}$ & $72(66$ to 76$)$ \\
\hline Residual volume & $99(90 \text { to } 108)^{\star \star}$ & 76 (67 to 85$)$ \\
\hline TLCO & $63(55 \text { to } 71)^{\star \star}$ & $38(30$ to 46$)$ \\
\hline Alveolar volume & 84 (77 to 92$)$ & 77 (70 to 84$)$ \\
\hline Kco & $78(70 \text { to } 87)^{\star \star}$ & $54(44$ to 63$)$ \\
\hline
\end{tabular}

${ }^{\star} \mathrm{p}<0.002,{ }^{\star \star} \mathrm{p}<0.001$

$\mathrm{FEV}_{1}=$ forced expiratory volume in one second, FVC $=$ forced vital capacity, TLCO $=$ carbon monoxide transfer factor, $\mathrm{KCO}=$ TLCO divided by alveolar volume.

a profusion grade greater than $1 / 0$ on the International Labour Office scale ${ }^{13}$ were seen in the chest radiograph in patients who had had substantial exposure to asbestos. In 11 patients in whom bronchoalveolar lavage was performed asbestos bodies were detected in bronchoalveolar lavage fluid. Cryptogenic fibrosing alveolitis was diagnosed on the basis of open lung biopsy in 12 patients and on clinical and plain radiographic evidence of interstitial lung disease in the other six. None of the patients with cryptogenic fibrosing alveolitis had been exposed to asbestos, had any symptoms or signs suggesting connective tissue disease or malignancy, had positive test results for avian precipitins, or had received any drug known to induce lung fibrosis.

\section{HIGH RESOLUTION COMPUTED TOMOGRAPHY}

All scans were carried out with an Elscint 2002 scanner with a scan time of $5.5 \mathrm{~s}$. We took $3 \mathrm{~mm}$ sections, $10 \mathrm{~mm}$ apart, from the lung apices to the bases in full inspiration at total lung capacity using a bone algorithm reconstruction. ${ }^{214}$ Window settings for lung fields (mean window setting 1602 Hounsfield units) and for soft tissue for clear identification of the pleura (mean window setting 621 Hounsfield units) were obtained in all patients. Additional sections were obtained in the prone position.

\section{INTERPRETATION OF SCANS}

High resolution computed tomograms were assessed by two independent readers. Lung fields were divided into three equal thirds, measured from apex to base. Readers were asked to identify the presence of emphysema, opacities suggesting fibrosis (linear, reticular,

Table 3 Distribution of shadowing in the upper, middle, and lower thirds of lung field in patients with cryptogenic fibrosing alveolitis (CFA) and asbestosis

\begin{tabular}{|c|c|c|c|c|c|c|}
\hline & \multicolumn{3}{|l|}{ Fibrosis } & \multicolumn{3}{|c|}{ Emphysema } \\
\hline & $\begin{array}{l}\text { Asbestosis } \\
n=24\end{array}$ & $\begin{array}{l}C F A \\
n=18\end{array}$ & pvalue & $\begin{array}{l}\text { Asbestosis } \\
n=24\end{array}$ & $\begin{array}{l}C F A \\
n=18\end{array}$ & pvalue \\
\hline Upper third & 6 & 10 & $<0.05$ & 11 & 13 & NS \\
\hline Middle third & 19 & 18 & $<0.05$ & 15 & 11 & NS \\
\hline Lower third & 23 & 18 & NS & 20 & 12 & NS \\
\hline
\end{tabular}
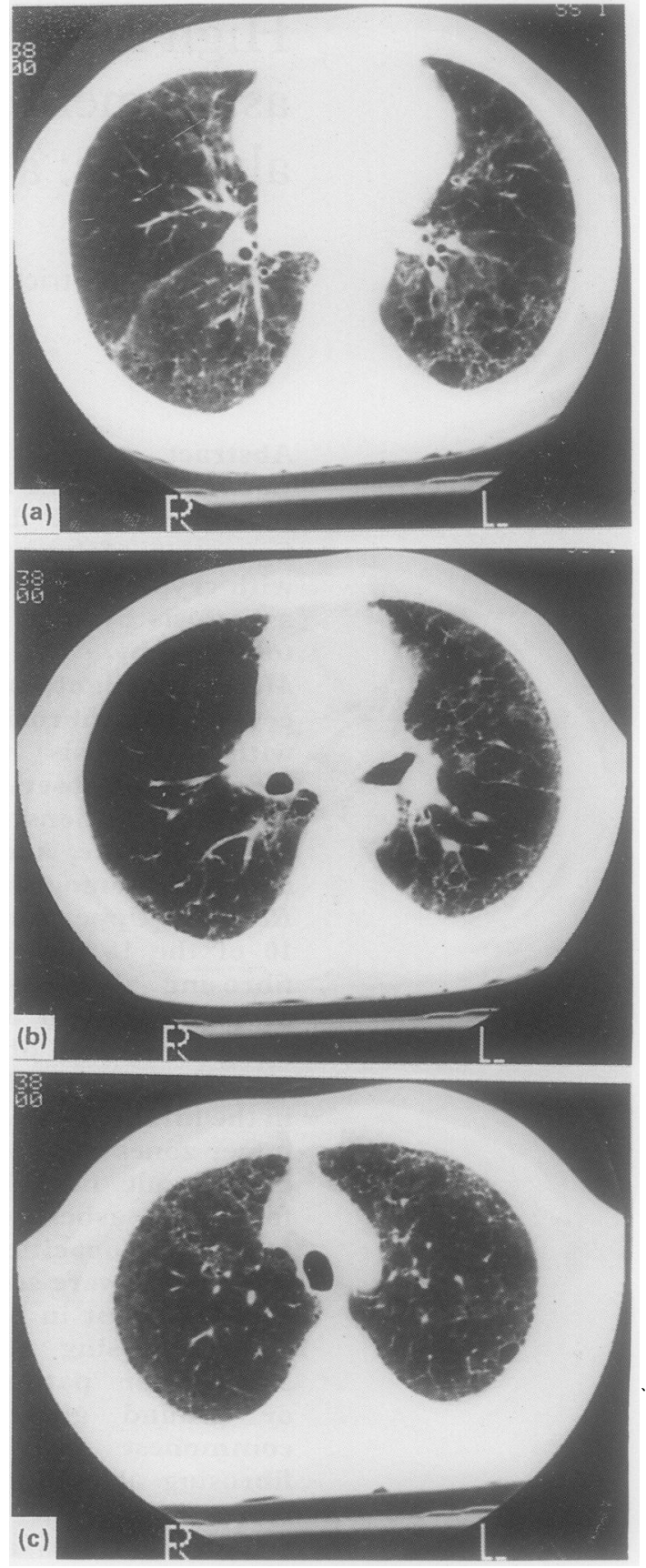

Figure 1 Cryptogenic fibrosing alveolitis: distribution of shadows. Fibrosis is predominantly posterior in lower sections ( $a$ ), lateral in middle sections (b), and anterior in upper sections (c). This distribution was seen in 11 $(61 \%)$ patients with cryptogenic fibrosing alveolitis and four $(17 \%)$ patients with asbestosis.

confluent, ground glass, honeycombing), and any pleural abnormalities in each lung zone. Readers also noted the distribution of the abnormal shadows present in the lung fields.

\section{LUNG FUNCTION MEASUREMENTS}

Patients did respiratory function tests within three weeks of undergoing high resolution computed tomography. Spirometry was done with a dry cylinder spirometer, single breath carbon monoxide transfer factor was measured with an Auto-link transfer factor machine, and lung volumes were measured with a computerised constant volume plethysmograph. Predicted values were calculated for age, sex, 
Table 4 Types and frequencies of opacities in asbestosis and cryptogenic fibrosing alveolitis

\begin{tabular}{|c|c|c|c|}
\hline Type of opacities & Asbestosis & $\begin{array}{l}\text { cryptogenic } \\
\text { fibrosing } \\
\text { alveolitis }\end{array}$ & $p$ value \\
\hline \multicolumn{4}{|l|}{ Crescentic fine reticular pattern with } \\
\hline Confluent or ground glass (fig 3) & $3 / 24$ & $14 / 18$ & $<0.00008$ \\
\hline Subpleural lines (figs 4 and 5) & $8 / 24$ & $4 / 18$ & NS \\
\hline \multicolumn{4}{|l|}{ Thick linear or band like densities in the } \\
\hline lower zones merging with the pleura (fig 7 ) & $18 / 24$ & $2 / 18$ & $<0.0002$ \\
\hline \multicolumn{4}{|l|}{ Wedge shaped or irregular densities closely } \\
\hline related to the pleura (figs 8 and 9) & $8 / 24$ & $0 / 18$ & $<0.007$ \\
\hline \multicolumn{4}{|l|}{ Pleural plaques and diffuse pleural } \\
\hline thickening & $21 / 24$ & $0 / 18$ & $<0.00001$ \\
\hline Rounded atelectasis (fig 10) & $6 / 24$ & $0 / 18$ & $<0.03$ \\
\hline
\end{tabular}

and height ${ }^{15}$ and results were expressed as percentages of predicted values.

\section{STATISTICAL ANALYSIS}

Age, pack years of smoking, and lung function measurements in patients with asbestosis and cryptogenic fibrosing alveolitis were compared by the Mann-Whitney U test.

The frequencies of disease in each of the lung thirds and type of shadows seen in the two conditions were compared by Fisher's exact test or the $\chi^{2}$ with the continuity (Yates) correction when the former test was inappropriate. Results were considered significant when $\mathrm{p}$ was less than $\mathbf{0 . 0 5}$.

\section{Results.}

There were no differences between the patients with asbestosis and cryptogenic fibrosing alveolitis in age or pack years of smoking (table 1). There were no significant differences between the groups for $\mathrm{FEV}_{1}$ or FVC, but the residual volume, total lung capacity, carbon monoxide transfer factor (TLCO) and TLCO divided by alveolar volume (KCO) were all higher in the asbestosis group (table 2).

Table 3 shows the distribution of opacities in lung thirds in the two conditions. Fibrosis in the lower zones was present in all patients in both groups; the upper and middle thirds were affected more often in cryptogenic fibrosing alveolitis than in asbestosis. In patients with cryptogenic fibrosing alveolitis the opacification tended to be most marked posteriorly in the lower zones, laterally in the middle zones, and

Figure 2 Asbestosis: diffuse cystic shadows in both lungs. Pleural plaque is present on lateral aspect of right lung (arrow).

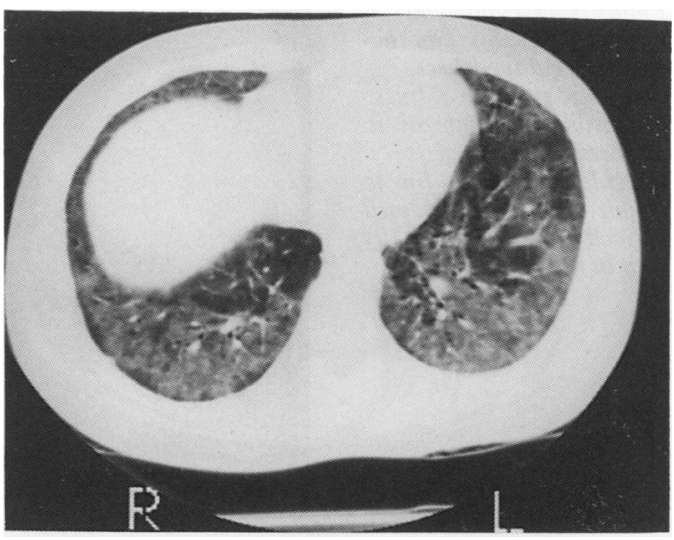

Figure 3 Cryptogenic fibrosing alveolitis: confluent shadowing in basal segments of lower lobes with irregular subpleural areas of low attenuation, especially on right. This "alveolar" type of change is rarely seen in asbestosis.

anteriorly in the upper zones (fig 1). This distribution was seen in $11(61 \%)$ patients with cryptogenic fibrosing alveolitis but in only four $(17 \%)$ with asbestosis $(p<0.003)$. We gained a qualitative impression that interstitial fibrosis and emphysema tended to be more distorting to lung architecture in cryptogenic fibrosing alveolitis than in asbestosis. Emphysema was not found in any of the non-smoking patients in either group.

Table 4 summarises the types of opacities and their frequency of occurrence in asbestosis and cryptogenic fibrosing alveolitis. In 15 of the 18 patients with cryptogenic fibrosing alveolitis there were areas of reticular or reticulonodular shadowing (fig 1). A fine honeycomb or cystic pattern with no or minimum pleural disease occurred in four of the 24 patients with asbestosis (fig 2). Areas of confluent and sometimes ground glass pattern, characteristically surrounded by a crescentic subpleural and paramediastinal transradiency, were seen in 14 patients with cryptogenic fibrosing alveolitis (fig 3) but in only three patients with asbestosis. Most patients with cryptogenic fibrosing alveolitis had areas of both reticular and confluent opacification.

Discrete subpleural lines were seen in a few patients with asbestosis and cryptogenic fibrosing alveolitis, the lines tending to be narrower in asbestosis (fig 4) than in cryptogenic fibrosing alveolitis (fig 5). Subpleural

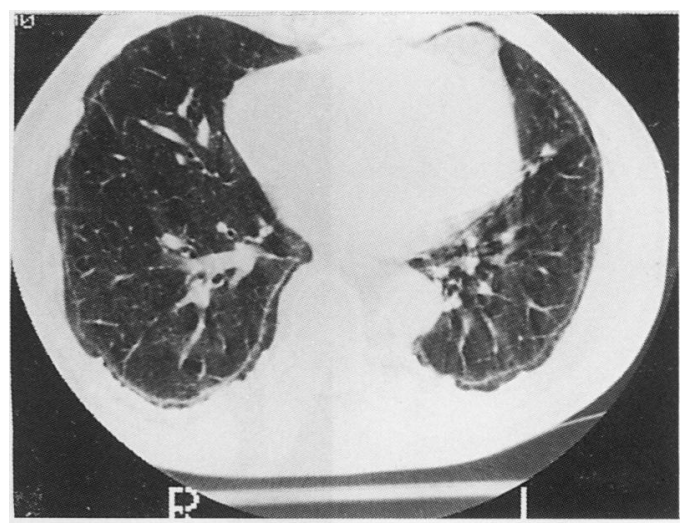

Figure 4 Asbestosis: narrow subpleural curvilinear lines parallel to pleural surface on both sides.

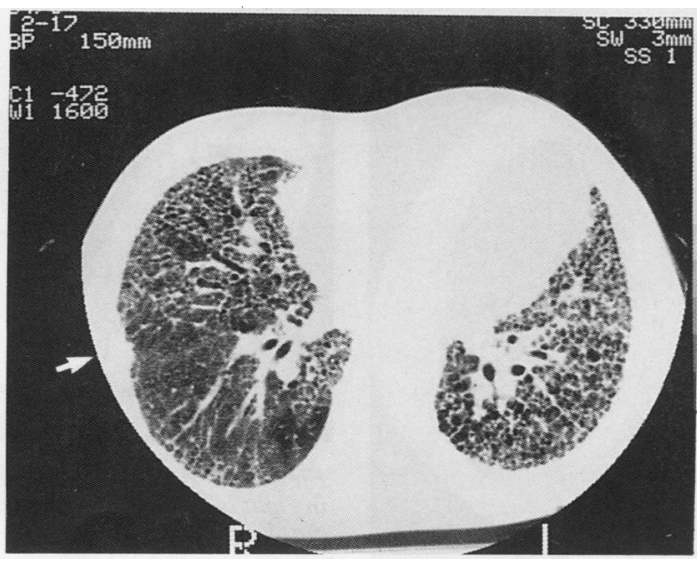


Figure 5 Cryptogenic fibrosing alveolitis: on the crescentic subpleural lines are visible where fibrosis is most severe; on the left irregular subpleural line is visible. The line is less well defined than that normally seen in asbestosis. right irregular, dense

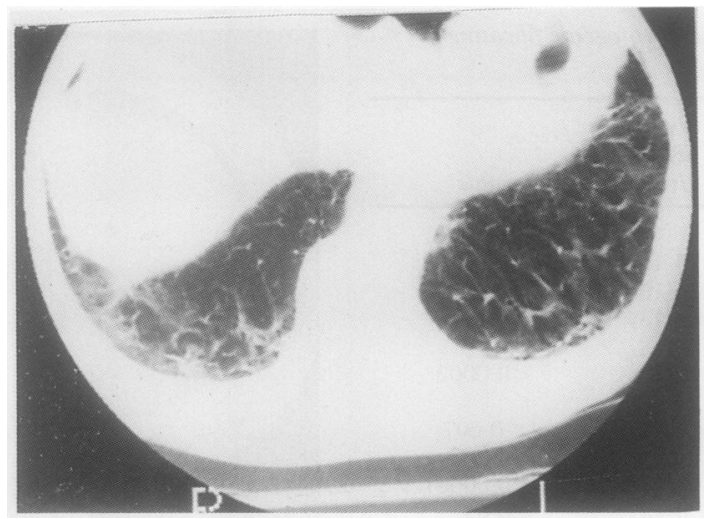

Circumscribed pleural plaques and areas of more diffuse pleural thickening were seen in 19 patients with asbestosis (fig 10), although in some the pleural thickening was minor in thickness and extent. Two further patients with asbestosis had pleural plaques alone, and three had no detectable pleural disease. Areas of rounded atelectasis due to pleural infolding (Blesovsky syndrome, figs 8 and 10) were seen in six patients with asbestosis and in none with cryptogenic fibrosing alveolitis. No definite pleural thickening was seen in cryptogenic fibrosing alveolitis, but multiple small peaks of density arising from the visceral pleura on both lateral and mediastinal surfaces were often present (fig 1).

lines were the only pulmonary abnormalities seen in three patients with asbestosis but were always associated with other types of interstitial opacities in cryptogenic fibrosing alveolitis. Two patients with asbestosis had discrete subpleural lines in the lower zones posteriorly which disappeared in the prone position (fig 6). Both patients had fine end inspiratory crackles on auscultation and the plain radiograph was interpreted as showing interstitial fibrosis.

Thick linear opacities perpendicular to the pleura were seen in the lower zones in 18 patients with asbestosis but in only two with cryptogenic fibrosing alveolitis (fig 7). Wedge shaped or curvilinear intrapulmonary opacities (figs 8 and 9) were seen in eight patients with asbestosis but were not identified in any patient with cryptogenic fibrosing alveolitis. These opacities were usually close to the pleura and merged with it, although in two patients they were wholly within the lung parenchyma (fig 9).

Figure 6 Asbestosis: (a) subpleural curvilinear lines in supine position in 63 year old former lagger;

(b) these lines disappear in prone position. This may represent early stage asbestosis, in which fibrosis is shown by summation effect of vascular shadowing.
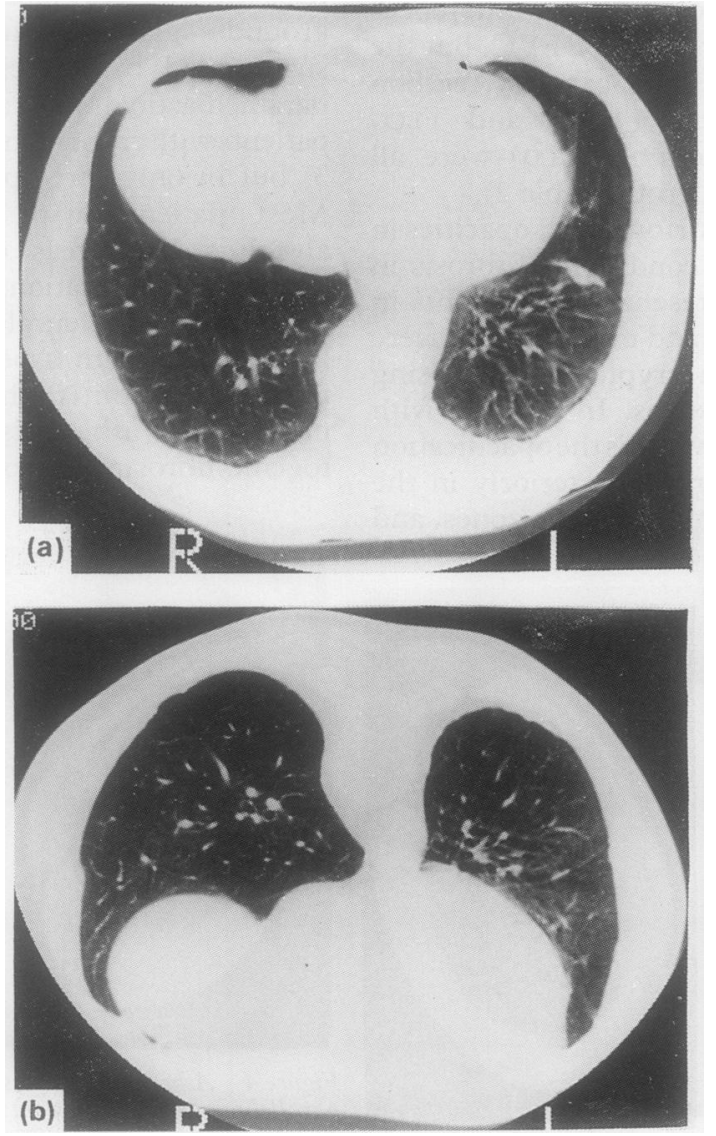

\section{Discussion}

The distribution and type of radiographic shadows in asbestosis and cryptogenic fibrosing alveolitis have not been compared systematically before, probably because the presence of pleural disease in asbestosis has been used as the prime differentiating radiographic finding. Pleural plaques are not invariably present in asbestosis, however, and in their absence these two conditions may be indistinguishable by chest radiography.

Our study suggests that features visible on high resolution computed tomograms aid differentiation between asbestosis and cryptogenic fibrosing alveolitis. Pulmonary fibrosis affecting the upper and middle thirds of the lungs was more common in cryptogenic fibrosing alveolitis than in asbestosis, in which fibrosis was often localised to the lower lobes. In cryptogenic fibrosing alveolitis a characteristic pattern of opacities in the posterior areas of the lower zones, the lateral areas of the middle zones, and the anterior areas of the upper zones was commonly seen; the posterior and lateral aspects of the upper zones appeared relatively normal. We also found that when asbestosis affected the anterior segments of the upper zones the abnormality was usually less severe than that seen in cryptogenic fibrosing alveolitis.

Confluent or ground glass opacities were

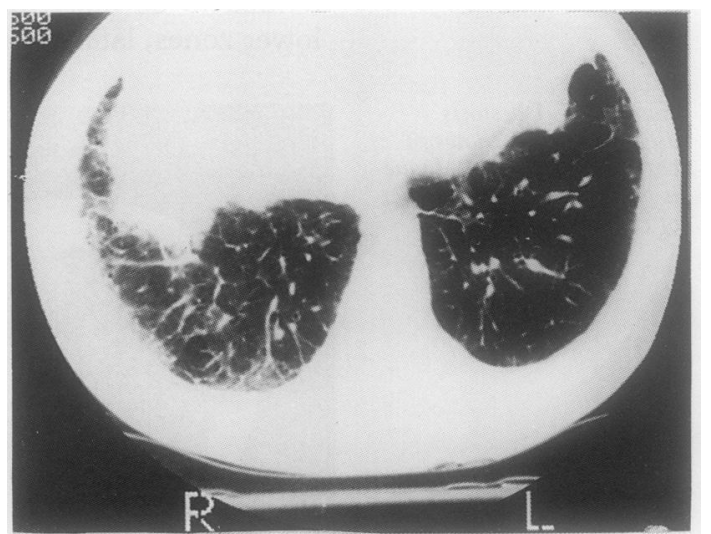

Figure 7 Asbestosis: coarse subpleural reticular pattern in right lung which merges with thickened posterior and diaphragmatic pleura. 
Figure 8 Asbestosis:on the left long thick irregular linear densities lie perpendicular to and merge with pleural surface and are associated with soft reticular density. On the right there is an irregular opacity attracting vessels and bronchi. Appearances on both sides may represent infolded lung in varying stages of evolution.

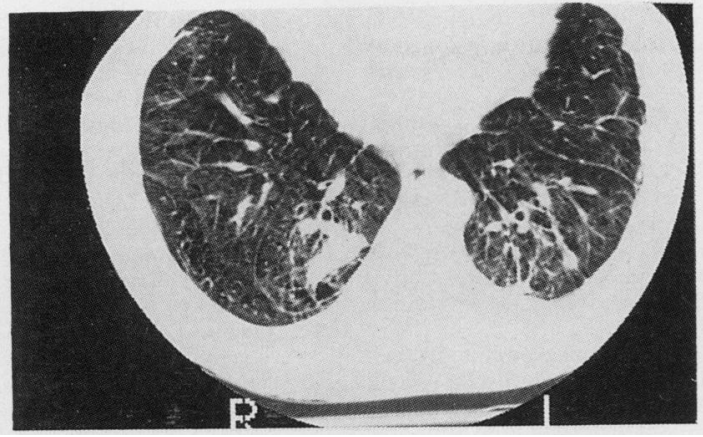

radiographic evidence of asbestosis in smokers compared with non-smokers. ${ }^{17-20}$

In asbestosis the commonest features were coarse linear opacities, often adjacent to pleural thickening. This pattern, which was seen rarely in cryptogenic fibrosing alveolitis, is believed to be due to interlobular and intralobular fibrosis. ${ }^{14}$ A fine regular cystic honeycomb pattern, as is often seen in cryptogenic fibrosing alveolitis, ${ }^{2}$ occurred in only a few patients with asbestosis.

Ventilatory capacity was slightly, although not significantly, lower in the asbestosis group than the cryptogenic fibrosing alveolitis group, but the residual volume and total lung capacity were higher, perhaps reflecting asbestos induced narrowing of the small airway. ${ }^{21-23}$

The carbon monoxide gas transfer and coefficient were more impaired in patients with cryptogenic fibrosing alveolitis, perhaps reflecting the more widespread distribution of the interstitial fibrosis. Pleural thickening may have contributed to relative preservation of the $\mathrm{KCO}$ value in some patients with asbestosis.

The question arises whether the more widespread distribution of opacities in patients with cryptogenic fibrosing alveolitis than in those with asbestosis reflects more advanced disease in the former group. This is unlikely to be the case. Fibrosis of upper zones in cryptogenic fibrosing alveolitis and the type of opacity were not confined to those with more severely impaired lung function but were seen at an early stage in some patients with mildly impaired lung function.

We conclude that the features seen on high resolution computed tomography which favour a diagnosis of cryptogenic fibrosing alveolitis include confluent (ground glass) shadows, reticulonodular and cystic shadows extending to the upper thirds of the lung field, and a characteristic pattern of posterior lower zone, lateral middle zone, and anterior upper zone opacities. Features that favour a diagnosis of asbestosis include pleural plaques or diffuse pleural thickening, thick band like opacities in the lower zones which extend to merge with the pleura, and isolated narrow subpleural curvilinear lines.

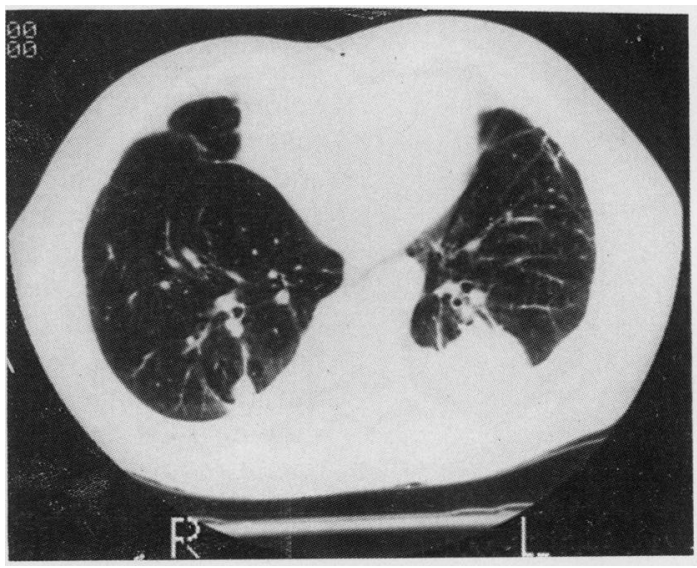

Figure 10 Asbestosis: posterior pleural based opacities in both lower zones probably represent infolded pleura and lung parenchyma (pseudotumours or Blezovsky syndrome).

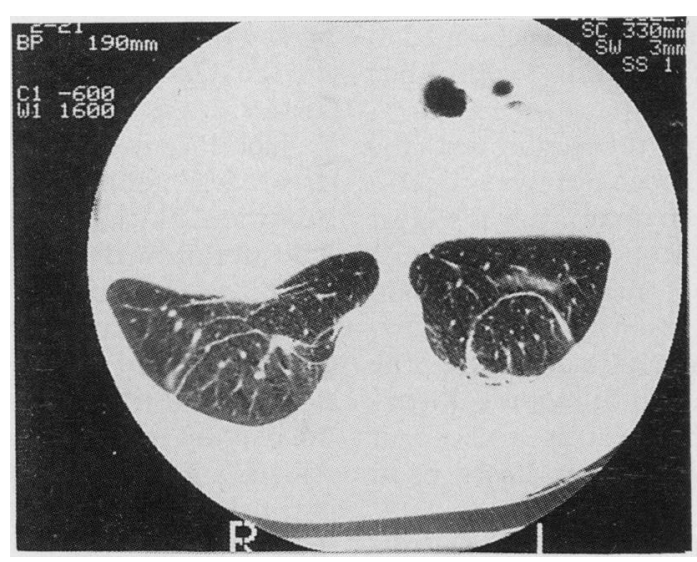

Figure 9 Asbestosis: on the right thick pleural based lines penetrate deep into lung field. On the left a thick curvilinear line is attached to pleura and extends into lung field, forming an arch within lung field. 
1 Zerhouni EA, Naidich DP, Stitik FP, Khouri NF, Siegelman SS. Computed tomography of the pulmonary parenchyma. II. Interstitial disease. J Thorac Imaging 1985;1:54-64.

2 Strickland B, Strickland NH. The value of high definition, narrow section computed tomography in fibrosing alveolitis. Clin Radiol 1988;39:589-94.

3 Bergin CJ, Muller NL. CT of interstitial lung disease: a diagnostic approach. Am J Radiol 1987;148:8-15.

4 Staples CA, Muller NL, Vedal S, Abboud R, Ostrow D, Miller RR. Usual interstitial pneumonia: correlation of CT with clinical, functional, and radiologic findings. Radiology 1987;162:377-81.

5 Muller NL, Miller RR. State of the art: computed tomography of chronic diffused infiltrative lung disease, part I. Am Rev Respir Dis 1990;142:1206-15.

6 Hansell DM, Kerr IH. The role of high resolution computed tomography in the diagnosis of infiltrative lung disease. Thorax 1991;46:77-84.

7 Nakata H, Kimoto T, Nakayama T, Kido MM, Miyazaki N, Narada S. Diffuse peripheral lung disease: Evaluation by high-resolution computed tomography. Radiology 1985; 157:181-5.

8 Staples CA, Gamsu G, Ray CS, Webb WR. High resolution computed tomography and lung function in asbestos workers with normal chest radiograph. Am Rev Respir Dis 1989;139:1502-8.

9 Aberle DR, Gamsu G, Ray CS, Feuerstein IM. Asbestosrelated pleural and parenchymal fibrosis: detection by high-resolution CT. Radiology 1988;166:729-34.

10 Yoshimura H, Hatakeyama M, Otsuji H, Maeda M, Ohishi $\mathrm{H}$, Uchida $\mathrm{H}$, et al. Pulmonary asbestosis: CT study of subpleural curvilinear shadow. Work in progress. Radiology 1986;158:653-8.

11 Akira M, Yamamoto S, Yokoyama K, Kita N, Morinaga $\mathrm{K}$, Higashihara $\mathrm{T}$, et al. Asbestosis: high-resolution CTpathologic correlation. Radiology 1990;176:389-94.
12 Mathieson JR, Mayo JR, Staples CA, Muller NL. Chronic diffuse infiltrative lung disease: $A$ comparison of diagnostic accuracy of CT and chest radiography. Radiology 1989;171:111-6.

13 International Labour Office. International classification of radiographs of pneumoconiosis. Geneva: ILO, 1980 radiographs of pneumoconiosis. Geneva. 2 (O), 1980.

14 Strickland B, Brennan J, Denison DM. Computed tomography in diffuse lung disease: Improving the image. Clinical radiology 1986;37:335-8.

15 Cotes JE. Lung function: assessment and application in medicine. 4th ed. Oxford: Blackwell Scientific 1979.281-7.

16 Wiggins J, Strickland B, Turner-Warwick M. Combined cryptogenic fibrosing alveolitis and emphysema; the value of high resolution computed tomography in assessment. Respir Med 1990;84:365-9.

17 Weiss W. Cigarette smoking, asbestos, and pulmonary fibrosis. Am Rev Respir Dis 1971;104:223-7.

18 Weiss W, Theodas PA. Pleuropulmonary disease among asbestos workers in relation to smoking and type of exposure. J Occup Med 1978;20:341-5.

19 Lilis R, Selikoff IJ, Lerman Y, Seidman H, Gelb SK. Asbestosis: interstitial pulmonary fibrosis and pleural fibrosis in a cohort of asbestos insulation workers: influence of cigarette smoking. Am J Ind Med 1986;10:459-70.

20 Kilburn KH. Clarification of data on the etiological role of cigarette smoking in pulmonary fibrosis. $\mathrm{Am} \mathrm{J}$ Ind $\mathrm{Med}$ 1984;5:421-2

21 Begin R, Cantin A, Berthiaume Y, Boileau R, Peloquin S, Masse S. Airway function in lifelong nonsmoking old asbestos workers. Am J Med 1983;75:631-8.

22 Cohen BM, Adasczik A, Cohen EM. Small airways changes in workers exposed to asbestos. Respiration 1984;45: 296-302.

23 Wright JL, Churg A. Severe diffuse small airways abnormalities in long term asbestos miners. $\mathrm{Br} J$ Ind Med 1985;42:556-9.

\section{Adventitia}

\section{My only private patient}

Foolishly I never did private practice. Foolishly because if you don't do private practice you are never going to see Elizabeth Schwarzkoff as a patient, or for that matter Madonna, and the money must come in handy-though when I started a consultant's salary was a living wage.

Almost 30 years ago a posh GP rang me up to say that he was sending me the 14 year old daughter of an American film producer-this on the advice of an American professor of paediatrics I had met in New York. The girl had been diagnosed in New York as having tuberculous glands of the neck and I was to continue her treatment with isoniazid alone. I didn't like the sound of that.

I found a rather sulky girl with bilateral cervical gland enlargement. The glands were quite large, up to about an inch in diameter, not tender, firm, and mobile. Not at all like tuberculous glands. What is more the girl's mother told me that the girl had started menstruating and that during the cycle the glands changed in size quite considerably; that didn't sound like tuberculosis either.

So I started by doing a tuberculin test (the New York diagnosis had been purely clinicalno investigations had been done). It was a Heaf test, the only one available in the chest clinic (a shop near Oxford Circus) and it is a very good test: it requires no skill, it is virtually painless, and, conveniently, it can be read at a week. The response was negative. So it wasn't tuberculosis (atypical mycobacteria as a cause of cervical adenitis had hardly been heard of in Britain at that time)

I rang the posh GP and told him that the girl would have to have a biopsy. The posh GP said he would arrange it. I assumed that this was the usual thing in private practice. He sent her to a urologist! A week or two later the answer came back. It was follicular carcinoma of the thyroid, which apparently is well known to occur in teenage girls. It wasn't well known to me. It was the first I had heard of it and the last. So I rang the posh GP and told him the girl should be sent to Jack Piercy, the surgeon superintendent of New End Hospital in Hampstead. New End was the name of a famous thyroid clinic originally started by London County Council. It had had several great men on its staffamong them Cecil Joll, who wrote a massive surgical textbook on the thyroid; Geoffrey Keynes (the brother of Maynard, the economist), who was the world authority on William Blake, and also Raymond Greene (the brother of Graham, the writer), who had been an Everest climber. Jack Piercy was the greatest of the lot. Two days later the posh GP rang me to say that Sir Ronald Bodley Scott, physician to the Queen, had said that we couldn't do better. I was very chuffed.

Jack Piercy told me in his letter that he had treated 17 similar patients by total thyroidectomy and block dissection of neck and that they had all survived. This girl underwent a successful block dissection of the thyroid. Many years later I heard that she was well (taking thyroxine as replacement therapy, of course).

I sent the film producer a bill for $£ 25$, which he paid by return but with no word of thanks.

I thought, "I will never be as lucky as that again so I'd better not see any more private patients," and I never did. 